Battalion, Seaforth Highlanders (Ross-shire Buffs, the Duke of Albany's): Surgeon-Captain J. Adam to be SurgeonMajor.

\section{ENTERIC Fever at Dagshai.}

It will be remembered that some time ago there was a severe outbreak of enteric fever at this Indian hill station and it was decided to evacuate it for a time until some improvements in regard to the water-supply and local sanitation had been effected. Dagshai was accordingly evacuated and the cantonments have been left empty during the last two seasons. Some cases of this fever have recently occurred among some drafts lately arrived at Dagshai from England. It is believed that the outbreak is not due, however, to any local causes but to the fact that the troops contracted the disease before their arrival at the station and brought the disease with them. An outbreak of the same disease is also reported from Chakrata among the troops newly arrived in the station. These appear to have left Meerut in good health and inquiry is accordingly being made into the condition of the camping stages along the route to discover, if possible, any causes which may account for the infection.

\section{The Philippine War.}

Military operations appear to be going on in the Philippines more actively than ever. There has quite recently been some fierce fighting although on a relatively small scale. The American forces apparently scored a marked success at Bacoor. General Otis is vigorously pushing on the campaign. The climate, at this season especially, must be giving rise to a good deal of inefficiency from sickness among the American troops.

Surgeon-General Sir Joseph Fayrer, Bart., K.C.S.I., retired list, I.M.S., has been granted an Indian Good Service Pension.

\section{Cortegpondente.}

"Audi alteram partem."

\section{THE CLAIMS OF CREMATION : A REPLY TO SIR FRANCIS SEYMOUR HADEN. \\ To the Editors of THW LaNCWT.}

SIRs,-Sir Francis Seymour Haden, in his paper in THE LANCET, ${ }^{1}$ commences with a statement that his communication is not intended to be controversial, but considering that it is throughout an attack on the practice of cremation and a defence of the earth-to-earth system of burial such a statement can hardly be considered accurate. The present letter is an attempt to answer the abovementioned paper and to put forward adequately the claims cremation possesses over other means of disposing of our dead.

The case for oremation.-1. Everyone who has any knowledge of, or interest in, sanitation recognises that the present system of burial in practically imperishable coffins is a bad system. The cemeteries of this country are rapidly becoming crowded with coffins containing dead bodies, potential sources of decomposition and putrefaction. These bodies are often those dead from infectious diseases and contain the germs of these diseases. These germs frequently find their happiest breeding ground in the soils of cemeteries and from this soil they may be, and frequently are, conveyed by water or other means to infect the living. It would hardly be necessary to quote facts in support of this assertion were it not that Sir Francis Haden has stated that the recent Milroy Lectures of Dr. Poore affirm the principle that disease is not conveyed in the earth. Now, the following extracts, quoted verbatim from the first Milroy Lecture, ${ }^{2}$ seem to me to prove the direct opposite of this: "Among the ubiquitous organisms which are habitually found in earth is the bacillus of tetanus. It is said to be present in almost all rich garden soils. ...... Marchesi has found it at a depth of two metres but no lower. ..... The statement made by Ledanteo and H. M. Stanley that the natives of the New Hebrides and Central Africa are in the habit of poisoning their arrows by smearing them with mud (obtained in the New Hebrides

1 THE LANCET, May 27th, 1899

2 TaE LANCET, Feb. 25th, 1899. from a mangrove swamp) gives emphasis to the importance of a tropical temperature and the absence of tillage as factors which make for increase of virulence of the tetanus bacillus and other oganisms found in earth." Surely this; supports the contention that to bury a body dying from tetanus and containing the germs of tetanus in the earth is to infect the earth and render it a possible source of infection to others. Again, quoting from the same source, Ernest Hart said: "Within certain areas in India cholera is endemic, especially in the country of the lower Ganges. There the air, the water, and the soil are never cold, the ground is often damp, and when it is dry the tanks are foul. so that there is always a fit breeding-place for the contagion." When we plant a body filled with this contagion in a medium so fitted for its cultivation we run a risk-a very serious riskof starting and spreading an outbreak of cholera. As a matter of fact, in the Board of Trade Reports a number of instances of epidemics of cholera directly traceable to the proximity of graveyards has been published. Dr. Friere of Rio de Janeiro has shown, too, that the organism of yellow fever multiplies in the soil of cemeteries in which countless numbers of germs are sown every time a body dead from yellow fever is buried and that it can be reproduced by water in which the soil of such places has been washed. These examples might be multiplied over and over again. Surely, then, it is not accurate to contend that the earth is not one of the methods by which infectious disease may be conveyed.

2. Recognising that some alteration is absolutely necessary in our present method of disposal of the dead the question to decide is what system is the best. The various means which have been either suggested or carried out may be classified as follows : (a) simple exposure to the air as practised by the Australian aborigines; $(b)$ committal to water as burial at sea, or to a river, as by some of the natives of India in their sacred river the Ganges ; (c) exposure to be eaten by vultures, as by the Parsees in the Towers of Silence at Bombay; $(\bar{d})$ disposal by desiccation ; $(e)$ ordinary burial in sealed coflins; $(f)$ buria in rapidly perishable coffins, or earth-to-earth burial; and (g) cremation. The first four of these systems possess such obvious disadvantages that no discussion on them is necessary. The objections to the fifth have already been considered, so that there remain only the earth-to-earth system (with which Sir Francis Seymour Haden's name is so intimately associated) and cremation. To my mind the fact that to bury a dead body in the earth, no matter whether in a perishable or an imperishable covering, is to pollute and contaminate that earth, to render that earth a potential source of infection of all kinds of diseases to living persons, by itself effectually disposes of the claims of this system as the one we should adopt. By cremation these dead bodies, these possible sources of putrefaction and disease, are rapidly and effectually transformed into harmless compounds instead of undergoing the revolting process of decomposition in the earth, and provided that the objections which have been urged against it can be overcome it is surely the ideal method of disposing of dead bodies.

3 . The objections to cremation may be discussed under the following heads : the sentimental, the religious, the sanitary, and the medico-legal. The sentimental objection is, from a scientific standpoint, unimportant. Time and education in matters of sanitation will effectually dispose of that-it is not one which need detain us. The religious argument against cremation is very feeble. It has been contended that the immortality of the body is jeopardised by its destruction in the furnace. The ultimate result of disintegration of the body is identical, whatever the process by which it comes about-namely, a resolution into its elementary constituents : it is simply a question of the length of time taken by the earth or by fire to do it and it is ridiculous to contend that the time taken by the body to be resolved into its components can have any influence on its subsequent immortality. Do those who use this argument believe that those martyrs who were burnt at the stake have thereby lessened their chances of resurrection? There is no real sanitary reason against the adoption of cremation as a universal custom. Sir Francis Haden says that on a large scale such a consumption and carbonisation of pure air would take place that a large area in the neighbourhood of the furnaces would be rendered uninhabitable. The answer to this is simple: with properly constructed furnaces the process of combustion is quite complete; no foul gas is allowed to contaminate the atmosphere. The analogy to the dust destructors which exist in our large towns and boroughs-e.g., St. Pancras and Shoreditch-is 
obvious. These are furnaces for the destruction of dead organic matter and they are found in practice to do this effectually and completely and they do not render either large or small areas uninhabitable, unsanitary, or unpleasant even when situated in a thickly populated district. The medico-legal argument is the one which has been most prominently pushed forward by the advocates of the earth-to-earth system. They contend that homicidal crimes such as secret poisoning and stabbing would be rendered less easy of detection consequent on the early and complete destruction of the body and therefore the impossibility of subsequent exhumation and so an increase in such crime would take place. Sir Francis Haden ${ }^{3}$ states that this is a part of the subject which no cremationist is willing if he can help it to hear mentioned. Now, so far from this being true, all cremationists recognise that this at first sight is a serious objection to their method and they have over and over again called attention to it publicly-for example, the speeches delivered by Dr. Cameron and Sir Lyon Playfair in the House of Commons on the Disposal of the Dead (Regulation) Bill on April 30th, 1884. ${ }^{4}$ As regards poisoning, experiments instituted by $M$. Cadet and repeated by M. Dourvault and M. Worst have shown that arsenic and all mineral poisons (except mercury) can be detected just as well in the ashes of a burnt body as they can be in an exhumed body. The organic poisons are destroyed just as much by interment as they are by fire, only, of course, not so quickly. But the remedy for this possible evil would be (and this is needed whatever system we adopt) to appoint State officials, as is done in France and Germany, to inquire into and verify the death certificate. In the majority of cases no difficulty would arise and in any suspicious case the proper anthorities could be notified and an investigation beld. The detection of crimes of this character is quite rare unless the criminal is discovered at once; after burial it is exceedingly uncommon for suspicion to arise. The average number of exhumations, for instance, in this country is only five per annum, and of these less than one is for suspected poisoning. As a matter of fact, crime would be more likely to be detected, not less, if we could make it statutory that a rerification of death should be undertaken by some independent official before a body is destroyed by cremation. To my mind the objections to cremation can all easily be disposed of. It is from all points of view the ideal system for adoption in the future for disposing of the dead.

I am, Sirs, yours faithfully,

L. A. PARRY, M.D. Lond., F.R.C.S. Eng., Honorary Anasthetist to the North-West London Hospital.

Bartholomew-road, N.W., May 30th, 1899.

THE GENERAL MEDICAL COUNOLL AND THE PROPOSED CONCILTATION BOARD.

\section{To the Editors of THE LANCET.}

SIRs,-It must be allowed, I think, that the idea of bringing together the representatives of the friendly societies and the members of the medical profession is a good one. At the same time it must be apparent that the General Medical Council have not gone sufficiently into detail in their scheme.

We are all aware that the friendly societies possess at the present moment a thoroughly workable organisation and that they are prepared at a very short notice to nominate and elect men to represent them on a conciliation board. On the other hand, it is evident that the medical profession have no such organisation to deal with such a question. The point which appears to me of the greatest importance is : How are the representatives of the medioal profession to be elected and by whom? I submit that neither the British Medical Association nor the medical defence societies could undertake such a duty. What I propose for the consideration of the profession is the formation of an association of medical officers connected with friendly societies. Let a conference be called of such officers at an early date and let it appoint a cummittee to formulate a scheme for the establishment of a permanent association. In the meantime perhaps you, Sirs will permit your columns to be used for the discussion of this very important subject. I cannot conclude without expressing the satisfaction which is felt with the decision of the General Medical Council in respect to the connexion of the medical profession with those particular associations which combine medical aid with life insurance.

I am, Sirs, yours faithfully,

Carliff, June 10th, 1899. T. GARRETT HORDER.

\section{To the Editors of THE LANCET.}

SIRs,-The resolution of the General Medical Council, "That this Oouncil regards it as unprofessional to hold the appointment of medical officer to associations which systematically practise canvassing and advertising for the purpose of procuring patients," is a step in the dark, and one which may involve endless troubles and worry to medical officers of clubs all over the country. Who is to decide what is systematic canvassing and advertising? All the large friendly societies canvass and advertise, but the Council dare not touch their medical officers, for they have a strong Parliamentary vote behind them. It is the medical officers of the small clubs, generally young struggling practitioners, who will be the ones to suffer. Some medical neighbour, smarting at some real or supposed interference with his patients, will report the club to the Council, and the medical officer dreading the expense and worry of defending himself, will have to resign. The result will be that the great friendly societies will soon exterminate the smaller clubs and our younger men will have to start as assistants to the present club medical officers and be sweated by them instead of obtaining independent practice. From a professional point of view the want of a wage limit and inadequate fees are far more objectionable than canvassing, for after all there are but few patients who will change their medical man at the request of an agent unless he can offer them better terms. The resolution of the Council practically makes the medical officer responsible for the action of all the agents of the association, with the fearful penalty of utter professional ruin if they are detected canvassing. If it applied to all clubs it would not be so objectionable, but a knowledge of modern politics teaches us that it can and will only be applied to the weaker ones. If the friendly societies refuse to accept a wage limit, which is the key to the whole matter, I fail to see what good can come out of the board of conciliation.

June, 1899. I am, Sirs, yours faithfully,

\section{THE MICROCOCCUS OF BERI-BERI.}

\section{To the Editors of THE LANCET.}

Sins,-I came recently across, in THE LANCET of June 25th, 1898, a communication from Dr. W. K. Hunter in which he speaks of a staphylococcus with rapid motion to be found in the blood of beri-beri patients and suggests that it may be the carse of the disease. I have long been cognisant of a micrococcus easily grown from blood and spleen on agar or gelatin, the growth being non-penetrating, greyish in colour, raised, and having very ragged edges. These cocci are most motile and the fresh blood in some cases is frequently crammed with them. With few exceptions the blood of all my beri-beri patients contained thom. Wishing to inoculate some animals with these cocci I was unable to obtain any whose blood was not already rich with them. Later I found that many healthy patients had them in quantities and still later that they were present in the blood of myself and other European officers. This was now nearly two years ago, since which time I bave been quite healthy and, I may mention, have never in my life suffered from any symptom of beri-beri or from fever of any description. A few of my patients suffering from beri.beri have had their blood quite free from the cocci throughout their attack. I have long come to the conclusion that the coccus is non-pathogenic and is contained in the blood of the majority of people living in this colony. Probably it is derived from meat, as so many animals possess it in such abundance.-I am, Sirs, yours faithfully,

\section{W. GrLMORE ElLIS,}

Medical Superintendent of the Government Singapore, May 8th, 1899. $\quad$ Lunatic Asylum, Singapore.

\section{THE PLAGUE COMMISSION. To the Editors of THE LANOET.}

SIRS,-My attention was only recently drawn by a friend to a report of the evidence taken by the Indian Plague Com. mission at Bombay and which is published in THE LANCET of Dec. 24th, 1898, p. 1740 . I find that I have been reported 